\title{
Study of Individual Differences in the Behavior of Mobile Technology Users in the Context of Urban Mobility
}

\author{
Marcia Cassitas Hino \\ EAESP FGV / ISAE \\ marciahino@uol.com.br
}

\author{
Maria Alexandra Cunha \\ EAESP FGV \\ alexandra.cunha@fgv.br
}

\begin{abstract}
With the accelerated process of urbanization, the Brazilian population is now $85 \%$ urban. In countries with emerging economies, the reduction in urban mobility has emerged as a major problem that affects both the economy and people's quality of life. The mobility difficulties faced in cities differ between men and women. This study uses the Individual Differences to Gender and IT (IDTGIT) theory [47] and investigates how individual differences influence the behavior of urban mobility service technology use. The research includes qualitatively structured interviews, questionnaires, and demonstrations. The results show the influence of individual characteristics and present five profiles of women in relation to their behaviors. This study enriches theory by demonstrating a new way to analyze this phenomenon By focusing on practice, the study contributes to the information available for companies seeking to facilitate access to urban mobility services and companies related to urban transport services.
\end{abstract}

\section{Introduction}

This study investigates intragender differences in women's use of technology in urban mobility services. This topic is relevant for women living in cities, and it has attracted the attention of international agencies and researchers. The United Nations [48] highlighted the global urbanization movement, which is particularly rapid in Brazil. By 2050, two-thirds of the world's population will be urban. This urbanization creates various problems, including urban mobility, which refers to the physical and virtual movement of people to access services such as education, health, work and leisure [27] [52]. The mobility difficulties faced in cities differ between men and women, especially in countries in the southern hemisphere. Studies on mobility have identified the influence of gender characteristics [22] [27]. Likewise, technology-use profiles are distinct among genders [36]. Thus, in this study, women were invited to participate in an investigation of use profiles and urban mobility applications. Through the lens of the Individual Differences to Gender and Information Technology Theory (IDTGIT) [44] [47] and using a mixed approach to collect and analyze data, this study sought to further the knowledge of the individual characteristics of women by outlining their use profiles in order to provide society and the government with information that supports and leverages the intragender agenda in the context of urban mobility.

According to UN estimates [49], the Brazilian population is now $85 \%$ urban. Approximately 178.17 million people of the more than 200 million total inhabitants live in cities. Urbanization has positive aspects. For instance, it leads to increases in the services supply capacity, economic opportunities, and investment in infrastructure; in short, it leads to better living conditions [26] [30]. However, it also has negative aspects, such as reductions in mobility [5], that must be understood and minimized. For countries with emerging economies, such as Brazil, the aspect most affected by urbanization is urban mobility [35]. With reductions in mobility, negative effects on the economy, the environment, and quality of life have been observed, especially in large cities in Brazil [39].

According to the latest census [25], the majority of women live in urban environments; however, the context of urban mobility is historically male [36]. With the development of cities and the urbanization movement, other mobility profiles have emerged. Technology has changed the relationship between mobility and gender as well as driven major innovations [53]. Several mobile applications have been developed to facilitate and assist users in their movement. Urban mobility applications have become an efficient commuting management alternative for users in Brazil [6]. However, the acceleration of the transformation of urban mobility requires more than technology. Gender issues must be systemically considered, both nationally and internationally, in 
mobility agendas. According to Lee [28], studies have linked women's mobility to economic opportunities, and some have argued that the technologies applied to mobility solutions have liberated women, enabling them to overcome physical and social barriers.

In this complex context, it is necessary to understand the factors that influence the different experiences of women in interactions between the use of technology and urban mobility services in Brazil. Although studies have investigated the problems of technology use in relation to gender, no studies have adopted an intragender perspective regarding the use of urban mobility service applications. Thus, this study focused on women users of urban mobility services on mobile phones, addressing the following research question: How do individual differences influence the behaviors of technology users of urban mobility services?

This article is divided into sections. After this introduction, which presents the context, Section 2 presents the theoretical framework, Section 3 presents the theoretical perspective, and Section 4 describes the methodological procedures adopted. The results are presented, analyzed, and discussed. The article concludes with final considerations, exploring its contributions and limitations as well as opportunities for future research.

\section{Theoretical Framework}

The concept of mobility can be understood in two different ways. It can refer to a physical movement from one place to another or a virtual movement in terms of access capacity [27] [52]. Physical mobility is related to the movement and transport of people, whereas virtual mobility or accessibility can be analyzed more deeply by considering two perspectives: access to a transport system and access to a destination [9] [27] [52]. Mobility has a direct effect on social mobility, providing a better quality of life through access to more and varied opportunities [52].

Mobile technologies have changed humancomputer interactions because they accompany users wherever they go, supporting them in various activities that were not previously possible [12]. The way in which people travel is being altered by urban mobility applications, which are used to map travel routes, verify traffic flows, and monitor transport in real-time, among other functionalities [3]. Taxi applications are considered urban mobility applications; instead of providing mobility information, however, they provide a commuting service. In addition to taxi applications, other applications have been developed to provide information that helps people move from one place to another by providing commuting routes, reference points, traffic information, toll information, information regarding the location of public transport, and the arrival and departure times for various places, among other information [19] [37].

In a review of more than 40 years of research on the relationship between ICTs and urban mobility, Cohen-Blankshtain and Rotem-Mindali [4, p. 1] identified a "growing body of research focusing on changing mobility patterns, changes in the experience of travel and changes in the perceptions of travel costs". The differences between and within genders in terms of mobility should be better documented in the literature [28]. Recognizing that the context of urban mobility is strongly characterized by gender differences, the examination of gender inequalities is the first step towards analyzing this issue [27]. "Gender and mobility are inseparable, influencing each other in profound and often subtle ways" [22, p. 1]. The different aspects of mobility reflect and influence aspects of gender empowerment, either differentiating them (i.e., strengthening the male-female hierarchy) or balancing them. The mere fact that women can access a location or work remotely changes certain aspects of the power relationship between genders [22]. One can also argue that gender influences mobility in terms of the various dimensions of mobility measurement, such as distance, time, duration, and the reason for commuting. Studies have indicated that women travel more often than men but with less displacement because they often leave their home to solve various problems. Hanson [22] consolidated several examples of these situations in her study. Vasconcellos [50] shared the view that gender influences mobility but for different reasons. According to this author, a division of tasks still exists in society between men and women, and this division affects the mobility of both genders. In addition to the division of tasks, safety is another aspect separating the genders [13] [27]. Women may stop traveling at night, refrain from traveling to certain places, or even opt for longer routes if these ways are considered safer. Montreal is one example of a place where women reduce their use of public transport at night for fear of violence [27].

The gender differences in information technology (IT) refer primarily to inequalities in access and use or to the perception of the existence of such inequalities; in other words, these differences reflect how much less women use or have access IT devices, facilities, or services [23]. The technology environment is predominantly male [20] [36] [44] [51], and access to technology among women is not a question of the availability of a computer with internet access. Various other aspects are related to women's access to technology [36]. The way in which the use of 
technology is presented can represent a concern for gender because research shows that women's limited access to technology results from limitations related to cost, having an appropriate profile, or both [20] [21] [42].

Various personal factors also affect decisions related to physical mobility [50]. Age is one of these factors; when people are young, commuting is motivated by education, and as time passes, the motivations change to work, social, and leisure activities. When older, people tend to reduce their mobility. Professions also affect mobility because certain jobs require more daily commuting than others. A person working in an office tends to have a different commuting profile than a traveling salesperson. Education is another influencing factor because individuals with more education tend to become more involved in activities outside the home. Income also affects mobility because it provides access to new mobility options and is directly related to the volume of resources dedicated to mobility. For example, lower social classes tend to move around on foot or by public transport, whereas people from higher social classes tend to commute using their own car. Marital status affects mobility, as married people often assume new responsibilities at home (e.g., regularly shopping at the supermarket). The mobility profile of a couple with children also differs from that of a couple without children.

\section{Individual Differences to Gender and IT Theory}

The choice of a study theory is a critical activity in research because it must ensure a broad, complete, and correct understanding of the reality under study. Studies relating gender to IT from the perspective of individual characteristics are recent and lack theory [1] [47]. The IDTGIT was chosen for this study for the following reasons. First, the technology field lacks theory but is related to this study's problem. Second, this theory enables the visualization of each participant; it does not consider gender as synonymous with sex, and it generalizes perceptions. Finally, this theory enables the recognition that individuals are formed by their experiences and influences.

Developed by Trauth, Quesenberry, and Morgan [47], the IDTGIT allows researchers to investigate individual variations within the same gender that result from a combination of personal characteristics, personal influences, and environmental influences. Furthermore, it focuses on intragender differences rather than intergender differences [45]. This theory was created in 2002 to understand the gender imbalance among IT professionals by analyzing the different experiences of women [33].

The initial version of the IDTGIT [44] encompassed two pillars: personal characteristics and sociocultural influences. In 2004, the theory was refined with the inclusion of a third pillar: environmental context [47]. Finally, in 2009, the names of the pillars were changed to better represent their content: the "personal characteristics" pillar was changed to "individual identity", the "sociocultural influences" pillar was changed to "individual influence", and the "environmental context" pillar was changed to "environmental influence" [46]. Figure 1 shows the pillars of this theory.

Figure 1. Pillars of the IDTGIT

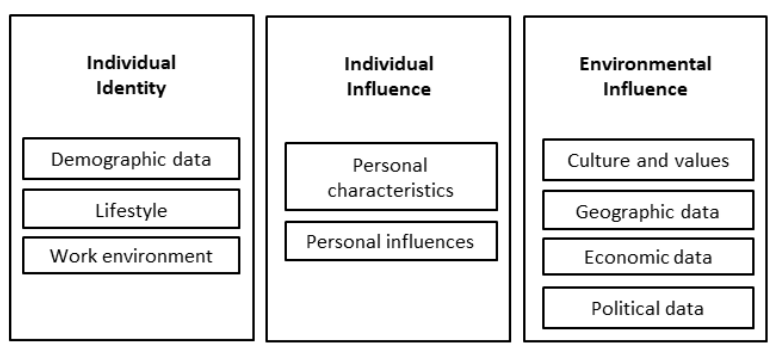

Source: Adapted from Trauth [46]

The first pillar of this theory refers to individual identity and is defined as the descriptive data of individuals, which might include a) demographic data, i.e., data representing individuals in population groups, b) lifestyle data, i.e., data describing the types of lives of individuals as well as their past and future, and c) work environment data, which refer to individuals' career information. The second pillar represents individual influences, i.e., people and experiences that have shaped who individuals are and how they make decisions, which includes personal characteristics and influences. The third pillar represents environmental influence, which contextualizes individuals by including attitudes linked to their cultures and values as well as their geographic, economic, and political data to provide sociocultural information [46] [47].

The IDTGIT is used by researchers across various contexts. Quesenberry and Trauth [38] investigated how ubiquitous computing is used to maintain the balance between one's work and personal life based on the perspective of women within the IT workforce. Cain and Trauth [8] investigated the existence and effect of stereotypes in relation to the scarcity of black men among IT professionals. In relation to the aspects of gender and ethnic culture, Richards and Busch [40] explored the existence of differences in perceived tacit knowledge and its use within the IT work environment. 


\section{Methodological Procedures}

This qualitative study collected data in Curitiba and São Paulo. Sao Paulo was selected because it is the most populous city in both Brazil and South America. Mobility is a critical issue in this city, even though the city has more than 14,000 buses, six subway lines, almost 34,000 registered taxis, and more than six million registered cars [2] [17] [31] [34]. Curitiba was chosen because it has differentiated urban solutions and quality of life indicators that stand out among the Brazilian capitals. According to the IBGE [24], Curitiba is among the five capitals in the country with the best human development index; of particular note is its leadership in mobility solutions [7].

Data were collected across three phases. Each participant was interviewed, completed a questionnaire, and demonstrated the use of certain applications on their mobile phones. The purpose of the interview was to identify and understand the use of technology in urban mobility services with regard to the daily routines of the participants and the influences exerted on their behaviors. A script of elaborate semistructured questions inspired by the IDTGIT was used. The Aspects of Identity Questionnaire (AIQ-IV) was used to measure individual characteristics through identity orientation. "Identity orientations refer to the relative importance that individuals place on various identity attributes or characteristics when constructing their self-definitions" [13, p. 1]. Based on 45 items that capture individual characteristics, the questionnaire classifies individuals into four identity orientation categories (Figure 2): a) personal identity, which represents self-perceptions and belief in oneself and includes psychological abilities and idiosyncrasies; b) relational identity, which represents how a person perceives herself with regard to interpersonal skills and the value she places on close relationships with friends and partners; c) social identity, which refers to beliefs about social groups; and d) collective identity, which represents the diverse identities of reference groups such as family and society.

Figure 2. Categories of individual differences

\begin{tabular}{|c|c|c|c|c|}
\hline $\begin{array}{l}\text { Category of } \\
\text { Individual } \\
\text { Characteristics } \\
\end{array}$ & Orientation & Description & Basis of Self-esteem & $\begin{array}{l}\text { Cultural } \\
\text { Differences }\end{array}$ \\
\hline Personal & Private & Traits, Values and Skills & $\begin{array}{l}\text { Personal aspirations and } \\
\text { standards }\end{array}$ & $\begin{array}{l}\text { Independent / } \\
\text { Individualistic }\end{array}$ \\
\hline Relational & Intimate & $\begin{array}{l}\text { Other people with whom } \\
\text { we have direct personal } \\
\text { contact }\end{array}$ & $\begin{array}{l}\text { Mutual respect, pride, and } \\
\text { validation by close others }\end{array}$ & 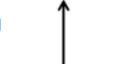 \\
\hline Social & Interpersonal & $\begin{array}{l}\text { Social roles and } \\
\text { reputation }\end{array}$ & $\begin{array}{l}\text { Public recognition and } \\
\text { compliments from others }\end{array}$ & \\
\hline Collective & Common Good & $\begin{array}{l}\text { Social categories to which } \\
\text { we belong }\end{array}$ & $\begin{array}{l}\text { Ethnic pride and pride } \\
\text { from belonging to social } \\
\text { groups }\end{array}$ & $\begin{array}{l}\text { Interdependent / } \\
\text { Collectivism }\end{array}$ \\
\hline
\end{tabular}

Source: Adapted from Cheek et al. [14]
The last data collection phase included a demonstration. Participants were instructed to access (using their own mobile phones) their installed urban mobility applications and to describe their use of the applications. This allowed the identification of behaviors such as choices made, settings selected, and location of the application on the phone. Data were collected during one interaction with each participant between June and July 2017. Figure 3 represents the data collection phases and the description of the methods used.

Figure 3. Sequence of the data collection phases

\begin{tabular}{|c|c|c|c|} 
Interview & Questionnaire & \begin{tabular}{c} 
Demonstration \\
\cline { 2 - 3 } $\begin{array}{c}\text { Semi-structured script } \\
\text { based on the individual } \\
\text { differences of gender and } \\
\text { information technology } \\
\text { theory [44] }\end{array}$
\end{tabular} & $\begin{array}{c}\text { Aspects of Identity } \\
\text { Questionnaire (AIQ) } \\
\text { version IV [13] }\end{array}$ \\
$\begin{array}{c}\text { Free } \\
\text { description by } \\
\text { the } \\
\text { participants }\end{array}$ \\
\hline
\end{tabular}

The participants were selected based on demographic elements related to the study, including city, sex, possession of a mobile phone with data access, and the use of urban mobility applications. A total of 34 women participated in the study. The data collection generated 1,159 minutes of recordings of the interviews and the demonstrations. All material was transcribed in its entirety for analysis.

The interview and demonstration information were qualitatively analyzed with Atlas TI®, which generated analysis categories. The categories of analysis began with those suggested by theory and were then expanded to more clearly capture each participant's intention. Quotations were associated with each category as the analysis process progressed. After the treatment of all information, the network was elaborated to assist in the graphical visualization of the information. The new analysis cycle was dedicated to data condensation, or the process of data abstraction and simplification, which occurs in every qualitative analysis process [32]. For example, the quotation "It's happened that Waze ${ }^{\circledR}$ offers me a path and I choose another because it looks more beautiful" was initially assigned to the environmental influence category but was later reassigned to the "cultural and values" subcategory. After this category was expanded, this quotation was linked to the "route selection criteria" category, which was finally consolidated into the "context identity" category.

The analysis of the questionnaire data followed the guidelines of Cheek, Smith, and Tropp [14], in which a value ranging from 1 ("not important") to 5 ("extremely important") is assigned for each response. After values were assigned to the responses, the scores were grouped by identity orientation category. The 
category, or categories, with the highest score for each participant indicated their identity orientation.

To define the behavior profiles, all of the information collected was evaluated jointly. The data condensation cycle also included the process of preparing qualitative data for a quantitative analysis. The quantification of qualitative data is a way of recognizing behavior patterns [41]. The categories mapped in the qualitative analysis step, as well as each response option, were transcribed into an Excel ${ }^{\circledR}$ matrix. The Excel ${ }^{\circledR}$ matrix was enriched with the data resulting from the questionnaire analysis. As a form of inspiration for the generation of profiles, statistical techniques were applied to the data with the support of Minitab. The multivariate analysis technique with clusters was used as the initial form of profile definition. For the validation and analysis of each profile, the regression results were transcribed into the Excel ${ }^{\circledR}$ matrix, and then, a qualitative and quantitative data interpretation was performed. After validation, a textual description of the profiles was performed.

\section{Presentation and Analysis of the Results}

Figure 4 shows the profile of the women who participated in the study, including information about their demographic characteristics and identity orientation.

\section{Figure 4. Participant characteristics}

\begin{tabular}{|c|c|c|c|c|c|}
\hline & 泀 & 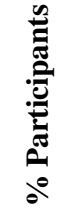 & 焉 & 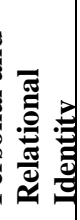 & 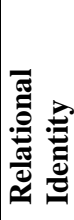 \\
\hline \multicolumn{6}{|l|}{ City } \\
\hline Curitiba & 19 & $56 \%$ & 11 & 3 & 5 \\
\hline São Paulo & 15 & $44 \%$ & 6 & 3 & 6 \\
\hline \multicolumn{6}{|l|}{ Age } \\
\hline$<=20$ years old & 10 & $29 \%$ & 5 & 3 & 2 \\
\hline 21-30 years old & 6 & $18 \%$ & 3 & - & 3 \\
\hline $31-40$ years old & 12 & $35 \%$ & 8 & 2 & 2 \\
\hline $41-50$ years old & 4 & $12 \%$ & 1 & 1 & 2 \\
\hline$>50$ years old & 2 & $6 \%$ & - & - & 2 \\
\hline \multicolumn{6}{|l|}{ Race (declared) } \\
\hline White & 26 & $76 \%$ & 13 & 4 & 9 \\
\hline Caucasian & 2 & $5 \%$ & 2 & - & - \\
\hline African Descendent & 2 & $5 \%$ & - & 1 & 1 \\
\hline Brown & 3 & $9 \%$ & 2 & 1 & - \\
\hline Mixture & 1 & $3 \%$ & - & - & 1 \\
\hline \multicolumn{6}{|l|}{ Religion (declared) } \\
\hline No religion & 11 & $33 \%$ & 7 & 2 & 2 \\
\hline Catholic & 16 & $47 \%$ & 8 & 2 & 6 \\
\hline
\end{tabular}

\begin{tabular}{|l|c|c|c|c|c|}
\hline Spiritism & 3 & $9 \%$ & 1 & 1 & 1 \\
Evangelical & 1 & $3 \%$ & 1 & - & - \\
Lutheran & 1 & $3 \%$ & - & - & 1 \\
Uninformed & 2 & $5 \%$ & - & 1 & 1 \\
\hline Income & 2 & $5 \%$ & 2 & - & - \\
\hline Up to 2 minimum wage & 2 & $5 \%$ & - & 1 & 1 \\
$2-4$ minimum wage & 11 & $33 \%$ & 7 & 3 & 1 \\
$4-10$ minimum wage & 7 & $21 \%$ & 3 & - & 4 \\
$10-20$ minimum wage & 12 & $36 \%$ & 5 & 2 & 5 \\
$>20$ minimum wage & 3 & $9 \%$ & - & 2 & 1 \\
\hline Education & 12 & $36 \%$ & 6 & 2 & 4 \\
\hline High School & 19 & $55 \%$ & 11 & 2 & 6 \\
Incomplete College & Completed College & \multicolumn{5}{|l|}{} \\
\hline
\end{tabular}

The profile of the participants initially suggests the existence of certain biases, such as those related to age, family income, and educational level. However, this aspect is related to the profile of users of mobile phones with internet in Brazil and reflects the profile of users of technology in urban mobility services. According to the Information and Communication Technology Households (TIC Domiciles) survey [16, p. 143], "the percentage of internet users who use mobile phones increases in accordance with the socioeconomic class". This use is above $90 \%$ among individuals in the highest socioeconomic class but lower than $50 \%$ in the two lower socioeconomic classes. This same survey stated that individuals with higher levels of education and income tended to have access to multiple connection platforms: Among the highest socioeconomic class, only $11 \%$ of users use only mobile phones to connect to the Internet, and "age is a factor that influences the use of computers and mobile phones to access the Internet" [16, p. 139]. This survey also highlights that users of lower social classes perform fewer activities via a mobile phone, which suggests that this use is associated with the need for greater speed and greater data consumption by applications.

Six of the thirty-four women participating in the research have two identity orientations: personal identity and relational identity. It is not uncommon for a person to have more than one identity orientation; it occurs when a person reaches the maximum number of points for more than one identity orientation. In addition, although two identity orientations from the literature did not appear among the participants, an identity orientation distribution among all demographic variables of analysis was verified.

The data analysis suggested the existence of a set of information related to a technology profile and another set of information related to the context under analysis. During the preliminary attempts to generate profiles, the theoretical lens used disregarded relevant information to define the profiles of the women. 
Several individual differences that originated from the participant demonstration process were not represented by the theoretical lens chosen, but they relate to the way users provide meaning to technology in the context of urban mobility. To incorporate such rich and relevant information in the profile analysis, a model for the use of mobility applications by women was developed. The model combined the 42 different categories that emerged from the analysis. In the model, the categories were organized into three identities. By understanding identity as a set of values, a process of generating meaning, a contextual identity, or even a fundamental construct [15], these sets of information were designated as IT identity, context identity and personal identity. This analysis resulted in a Technology-Use Behavior Model (Figure 5).

Figure 5. The Technology-Use Behavior Model

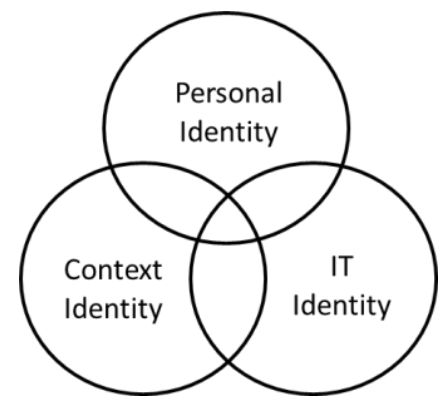

This model suggests that technology-use behaviors are caused by three identities: personal identity, context identity, and IT identity. Personal identity captures individual characteristics, including individual identity as well as environmental influences that shape this identity. Context identity represents the characteristics of individuals in a studied context; thus, its constructs vary according to the analyzed context. In this study, the context was urban mobility. The characteristics of context identity are found in the studies of Vasconcellos [50], Françozo and De Mello [19], and Castro and Tedesco [10]. Examples of context identity variables include the use intensity of applications as well as the reasons for using mobility applications. Finally, IT identity represents the individual's position in relation to technology or how she gives meaning to technology [10].

Figure 6 shows the constructs that describe the identities in the Technology-Use Behavior Model. The variables are distributed according to their relationship with the identities in the model. This model explains the existence of variables with a shared meaning; for example, the "mobility routine" variable, which is a context identity variable influenced by personal identity through the "age" variable, was also found by Vasconcellos [50].
Figure 6. List of constructs

\begin{tabular}{|c|c|c|}
\hline $\begin{array}{l}\text { Personal } \\
\text { Identity }\end{array}$ & $\begin{array}{l}\text { Context } \\
\text { Identity }\end{array}$ & IT Identity \\
\hline $\begin{array}{l}\text { - Age } \\
\text { - Income } \\
\text { - Education } \\
\text { - Race } \\
\text { - Religion } \\
\text { - Marital status } \\
\text { chimber of } \\
\text { - Identity } \\
\text { - orientation } \\
\text { - Self- } \\
\text { description }\end{array}$ & $\begin{array}{l}\text { - Routine } \\
\text { mobility path } \\
\text { - Profile } \\
\text { locomotion } \\
\text { - Location } \\
\text { sense } \\
\text { - Routine } \\
\text { mobility } \\
\text { transportation } \\
\text { - Reason for } \\
\text { routine } \\
\text { mobility } \\
\text { - Reason for } \\
\text { changing } \\
\text { routine } \\
\text { mobility } \\
\text { transportation } \\
\text { - Knowledge } \\
\text { of rights and } \\
\text { duties } \\
\text { - Service } \\
\text { change } \\
\text { possibility } \\
\text { - Route } \\
\text { selection } \\
\text { criteria }\end{array}$ & $\begin{array}{l}\text { - Reason for using apps } \\
\text { - How did you know the } \\
\text { apps? } \\
\text { - Alias creation } \\
\text { - Profile use technology } \\
\text { - Paper technology in life } \\
\text { - Forms of identify } \\
\text { expression } \\
\text { - Apps interface } \\
\text { - Privacy and personal } \\
\text { information in apps } \\
\text { - Locator apps } \\
\text { - App indication } \\
\text { - Intensity of app use } \\
\text { - App interaction } \\
\text { - Payment management } \\
\text { apps } \\
\text { - App organization } \\
\text { - How you learned to use } \\
\text { apps } \\
\text { - App evaluation log } \\
\text { - App maintenance } \\
\text { App setup and } \\
\text { functions } \\
\text { - Tho also uses apps } \\
\text { - Sime use apps } \\
\text { - App device } \\
\text { - Mobile apps page } \\
\text { - Search form in apps }\end{array}$ \\
\hline
\end{tabular}

The model finds support in the fact that different identities interact harmoniously, which reinforces shared meanings [10], [11], [18], [43]. Consequently, different identities share common meanings by establishing behavioral profiles between the areas.

The Technology-Use Behavior Model enables the identification of five profiles of women who use urban mobility service technology.

The first profile characterizes a safe and technological woman. The woman in this profile is between 36 and 45 years old and is typically single. She is an established woman but still worries about professional matters. Her identity profile orientation varies between her personal interests and goals and the development and maintenance of her relationships with others. This woman has a sound sense of space and direction, positioning herself well with regard to mobility. Her decisions related to urban mobility are guided by aspects of ease of use and low cost. Cost and safety stand out as factors that would make her change her routine mobility. Mobility is important in choosing a service she needs, but it is not always the imperative factor. Technology is essential in her life, keeping her connected to everything concerning technology, and she uses the available settings of technological services to her advantage. She is confident in using technology. 
For this woman, the motives that encourage her use of mobility applications are as follows: ease of use, organization and personal planning, and the aggregation of information that she needs. She recommends the use of the applications to other people.

The second profile characterizes a discreet and basic woman. She is between 30 and 35 years of age and typically married, financially stable, and focused on her personal needs. Her identity orientation is personal; that is, she is focused on herself, her needs, and her goals. She considers her role in society as important, and the feedback she receives from mentors shapes her development. She is conservative in matters of mobility and values low cost, speed, and safety. Only two things make this woman change the way she moves in an urban environment: unavailability or difficulty of use. This woman is unconnected to technological advances; basic use is enough for her. She views technology as a means for achieving her goals. Most of the mobility applications that she uses came preinstalled with her phone purchase, and she started using them naturally. She is concerned about the privacy of her personal information, and for this reason, she provides only the minimum information necessary for the applications to function.

The third profile represents a woman who is experiencing self-discovery. This woman is less than 23 years of age, single, and has a variable income. Her personality orientation is focused on her goals and needs. She is open-minded and concerned about her career, her orientation, and her role in society. This woman does not have a strong sense of location, space, or direction. She always uses the same mobility transportation options, changing only at night. Her position regarding mobility is one of safety and speed; however, she indicates that she would be comfortable with changing her mobility options. She is considered indifferent with regard to the use of technology; she is not resistant to its use but also does not consider its great benefits. She learned about her urban mobile applications through recommendations and learned how to use them alone, although some evidence suggests that friends helped her. Even without her realizing it, her application use profile is intensifying. Among her main reasons for using mobility applications are the possibility of determining her location, figuring out how to get to where she wants to go, and obtaining commuting information.

The fourth profile characterizes a practical and decisive woman. This woman is over 45 years of age and Catholic, and she has typically completed higher education. Her income is more than 20 times the minimum wage. She is focused on her relationships, and she is a dynamic woman. For her, mobility is synonymous with convenience, ease, and safety, and she tends to change her mobility profile on weekends. She likes to vary her routine mobility path. In general, she prioritizes routes with less traffic. The mobility cost is irrelevant to her. Her technological profile is conservative. She considers technology important in her life, although she does not have a profile of recording service-related compliments, complaints, or suggestions. She uses mobility applications to learn about regions to which she is traveling. In general, mobility applications are not grouped on her mobile devices. Her position seems to be "experiencing the beautiful things in life" without much worry.

The fifth profile is that of a free and independent woman. Aged between 24 and 30 years old, this woman is single. Her personality orientation is focused on herself, her thoughts and emotions, and her goals. Her possessions are important to her. At present, her role in society is not important, nor is her social class or economic group. She considers herself safe and dynamic, and her choices regarding work and her professional career are important to her. For her, mobility is related to freedom. The only thing that would make her change her routine mobility option is a change in her routine that would affect her choices. For this woman, technology is almost a necessary evil, and its use is closely related to her work; otherwise, she would not use it much. She learned about her applications through friends and family. She does not make recommendations to other people. Her interaction is greater than what she perceives because although she reports that she does not record servicerelated information, compliments, or suggestions, she makes complaints where appropriate. Her primary motivation in using mobility applications is to identify her location. Figure 7 consolidates the profiles identified.

Figure 7. Consolidation of profiles

\begin{tabular}{|c|c|c|}
\hline \multicolumn{3}{|c|}{ Profile (\% of participants) } \\
\hline Personal identity & Context identity & IT identity \\
\hline \multicolumn{2}{|c|}{ Profile 1: Safe and technological (20.6\%) } \\
\hline $\begin{array}{c}\text { Decisive and } \\
\text { positions herself; in } \\
\text { transition between } \\
\text { focusing on herself } \\
\text { and focusing on } \\
\text { relationships }\end{array}$ & $\begin{array}{c}\text { Constant but can } \\
\text { vary at night; cost, } \\
\text { ease, and safety are } \\
\text { important }\end{array}$ & $\begin{array}{c}\text { Connected, active, } \\
\text { and confident in the } \\
\text { use of technology }\end{array}$ \\
\hline \multicolumn{3}{|c|}{ Profile 2: Discreet and basic (17.6\%) } \\
\hline $\begin{array}{c}\text { Mobility options } \\
\text { vary on the }\end{array}$ \\
$\begin{array}{c}\text { Dynamic, } \\
\text { establishing herself } \\
\text { in life and in society } \\
\text { because of the } \\
\text { difficulty of use; }\end{array}$ & $\begin{array}{c}\text { Is not very } \\
\text { technology (basic is } \\
\text { enough) }\end{array}$ \\
\hline \multicolumn{3}{|c|}{ Profile 3: Experiencing self-discovery (35.3\%) } \\
\hline Open-minded; & Does not have a & Is indifferent to \\
\hline
\end{tabular}




\begin{tabular}{|c|c|c|}
\hline $\begin{array}{l}\text { experiencing self- } \\
\text { discovery; listens to } \\
\text { others and is } \\
\text { concerned about } \\
\text { society }\end{array}$ & $\begin{array}{l}\text { strong sense of } \\
\text { location; changes } \\
\text { routine because of } \\
\text { safety }\end{array}$ & $\begin{array}{c}\text { technology, } \\
\text { although her profile } \\
\text { indicates that her } \\
\text { usage has } \\
\text { intensified, even } \\
\text { without her } \\
\text { realizing it }\end{array}$ \\
\hline \multicolumn{3}{|c|}{ Profile 4: Practical and decisive $(14.7 \%)$} \\
\hline $\begin{array}{l}\text { Mature, dynamic, } \\
\text { and focused on } \\
\text { society and } \\
\text { relationships. }\end{array}$ & $\begin{array}{l}\text { Position seems to be } \\
\text { "experiencing the } \\
\text { beautiful things in } \\
\text { life" without } \\
\text { worrying about } \\
\text { goods or services }\end{array}$ & $\begin{array}{l}\text { Technology is } \\
\text { important, although } \\
\text { she is afraid of } \\
\text { using it and is } \\
\text { generally motivated } \\
\text { by circumstance }\end{array}$ \\
\hline \multicolumn{3}{|c|}{ Profile 5: Free and independent $(11.8 \%)$} \\
\hline $\begin{array}{l}\text { Safe, dynamic, and } \\
\text { extremely focused } \\
\text { on her needs }\end{array}$ & $\begin{array}{c}\text { Mobility is the } \\
\text { sensation of } \\
\text { freedom with } \\
\text { safety; values traffic } \\
\text { little } \\
\end{array}$ & $\begin{array}{c}\text { Technology is } \\
\text { considered a } \\
\text { necessary evil and } \\
\text { is used primarily for } \\
\text { work }\end{array}$ \\
\hline
\end{tabular}

The results suggest that individual differences influence technology-use behaviors in relation to urban mobility services, revealing five distinct technologyuse behavior profiles among women. The findings corroborate previous studies that have analyzed individual factors in the technology adoption process or the influence of individual factors on urban mobility decisions. Venkatesh and Morris [51] considered personal characteristics (specifically, age) as an influencing factor when defining their model for the acceptance and use of technology.

The reasons for using urban mobility applications identified by this study differ from those presented by Françozo and De Mello [15]. This study found evidence that women use mobility applications for safety, planning, self-organization, locating themselves, avoiding traffic, obtaining information, learning about a region, having autonomy, and convenience. In contrast, Françozo and De Mello [19] listed reasons such as searching for routes with a higher speed limit, receiving alerts about accidents and police radar, obtaining information about safety, and forecasting the time of arrival. This discrepancy is attributed to the profiles of the participants in the two studies. The present study focused only on women, whereas François and De Mello [19] did not specify gender, which leads us to believe that the profile was mixed. The use intensity of applications is another variable that appeared in both studies, but in this case, the behaviors were similar, i.e., use for both routine and unknown routes. The interface of the applications was a concern for all users [10]. The importance of safety-related factors might differ between other countries and Brazil.

One type of behavior that was identified is independent of technology and personal characteristics, i.e., the use of more than one mobility application. This study, which included only women, identified the predominant use of more than one application among the participants. Indications of this behavior were also identified by Françozo and De Mello [19].

\section{Final Considerations}

This study investigated women's use of mobile urban mobility applications in Curitiba and São Paulo. This study sought to understand how individual differences influence the behavior of urban mobility service users. In accordance with Luciano et al. [29], who argued that the use of theories in the development of studies contributes to the quality of the final result, the present study was conducted under the umbrella of the IDTGIT, created by Trauth, Quesenberry, and Morgan [47]. With the aid of this theory, a model was developed that allowed us to identify five behavior profiles.

Information on individual characteristics and the urban mobility of women is important for society and can be considered a motivational factor for the use of technology. This study provided evidence of individual differences in the behavior of urban mobility service users. Five distinct behavior profiles were identified and described: the safe and technological woman; the discreet and basic woman; the woman experiencing self-discovery; the practical and decisive woman; and the free and independent woman. The definitions of these profiles enable visualizations of how individual characteristics are relevant in this context.

This study contributes to theory advancing research on how individual differences influence the behavior of technology users, extending it to the urban mobility environment. The study analyzes how individual differences influence the behavior of urban mobility service technology use based on an established theory and understands the phenomenon from the perspective of three identities: personal identity, context identity, and IT identity. It also addresses the dichotomous statistics between "women's mobility" and "men's mobility" [28] found in the literature, presenting different women's mobility profiles. This new investigation perspective calls for future studies, specifically with regard to the improvement and refinement of these identities into constructs within the framework of definitions and empirical tests.

With regard to this study's contributions to practice, the results could be explored at city, state and country levels. Intragender studies are needed 1) to highlight women's individual differences in order to provide public policy managers of urban mobility with more accurate information, thus improving existing policies; 2) to generate knowledge for companies that facilitate access to urban mobility services; 3 ) to 
provide more detailed interpretations of gender characteristics that differentiate the use of technology in urban mobility services to companies in the urban transport service chain; 4) encourage reflections on the gender characteristics associated with the use of urban mobility services; and 5) to contribute towards improving the use of technology in urban mobility solutions by encouraging debate on the subject in order to highlight current perspectives. In addition, the influence of individual differences that contribute to a female inclusion strategy must be considered in making these urban mobility services more aligned with the needs of women.

The research has some limitations. Nevertheless, the profiles require further empirical validation. The main limitation is related to the participant selection, including the size of the sample, the lack of coverage of all identity orientation profiles and the concentration of certain personal characteristics among participants, such as marital status and number of children.

Finally, future research can validate, from a quantitative perspective, the five profiles identified and the proposal of the new perspective of information analysis. Other opportunities for future research include the analysis of profile comparisons among different cities; the exploration of behavior profiles in public mobility policies; the quantitative validation of the Technology-Use Behavior Model; investigations of the influence of individual differences in the services available to technology users; the identification of variables that better define IT identities in the context of individual differences and technology use; understanding the intragender perspective within the technology adoption process; assessing the effect of adopting characteristics of individual differences in the development of technology services; and the replication of this study with men.

\section{References}

[1] Adam, A., Howcroft, D. and Richardson, H. "Absent friends? The gender dimension in information systems research", In: Realigning Research and Practice in Information Systems Development. Springer, 2001, pp. 333352.

[2] Adetax. "Estatísticas. 2015". URL: http://www.adetax.com.br/index.php/informacoes-e-

servicos/estatisticas/ Visited on 28.Jan.2018.

[3] Almeida, R. L., Mesquita, L. B. M., Carvalho, R. M., Junior, B. R., and Andrade, R. M. "Quando a tecnologia apoia a mobilidade urbana: Uma avaliação sobre a experiência do usuário com aplicações móveis." In: Proceedings of the XV Brazilian Symposium on Human Factors in Computer Systems (IHC 2016). Brazilian Society of Computation-SBC, Porto Alegre, Brazil. 2016.
[4] Cohen-Blankshtain, G., \& Rotem-Mindali, O. "Key research themes on ICT and sustainable urban mobility". International Journal of Sustainable Transportation, p. 9-17. 2016.

[5] Boareto, R. A. "Política de Mobilidade Urbana e a Construção de Cidades Sustentáveis". Journal of Public Transport -ANTP-Ano, 30, 2008, pp. 143-160.

[6] Boechat, L. "Smart Technologies for Urban Mobility in Brazil". URL: https://techinbrazil.com/smart-technologiesfor-urban-mobility-in-brazil Visited on 08. Feb.2018.

[7] Bugs, G. "Modelos de Gestão de Projetos Urbanos. Revista Iberoamericana de Urbanismo ", 1, 2009, pp. 41-56.

[8] Cain, C. C.; Trauth, E. M. "Stereotype Threat: The Case of Black Males in the IT Profession". In: Proceedings of the 2013 Annual Conference on Computers and People Research, 2013, pp. 57-62.

[9] Cardoso, C. "Análise do Transporte Coletivo Urbano sob a Ótica dos Riscos e Carências Sociais". Thesis (Doutorado em Serviço Social), Pontifícia Universidade Católica, São Paulo, 2008.

[10] Carter, M..; Grove, V. "Me, Myself, and I(T): Conceptualizing Information Technology Identity and its Implications". MIS Quarterly, 2015, pp. 931-957.

[11] Castells, M. "The Power of Identity: The Information Age: Economy, Society, and Culture". John Wiley \& Sons, 2011.

[12] Castro, M. F.; Tedesco, P. "Aplicação de Conceitos de Wayfinding em Interfaces Mobile de Recomendação de Rota". Technical Tracks. Recife, 2014.

[13] Chant, S. "Cities Through a 'Gender Lens': A Golden 'Urban Age' for Women in the Global South?", Environment and Urbanization, 25, 2013, pp. 9-29.

[14] Cheek, J. M.; Smith, S..; Tropp, L. R. "Relational Identity Orientation: A Fourth Scale for the AIQ". In: Meeting of the Society for Personality and Social Psychology, Savannah, GA. 2002.

[15] Collins, D." Feminist Identity". Thesys. (Phin Psychology). Faculty of Virginia Polytechnic Institute and Virginia State University. 2001. URL: http://theses.lib.vt.edu/theses/available/etd-04262001-

194845/. Visited on 24. Jan.2017

[16] Internet Steering Committee in Brazil (CGI). "Pesquisa sobre o uso das Tecnologias da Informação e da Comunicação no Brasil: TIC Domicílios 2016”. São Paulo: Centro de Estudos sobre as Tecnologias da Informação e da Comunicação-CETIC. $\quad$ Brazil, $2017 . \quad$ URL: http://www.cetic.br/media/docs/publicacoes/2/TIC_DOM_20 16_LivroEletronico.pdf Visited on 24. Jan.2018.

[17] São Paulo Transit Department (DETRAN-SP). "Frota de Veículos em SP - por tipo de veículo. 2017 ". URL: https://www.detran.sp.gov.br/wps/wcm/connect/portaldetran/ detran/detran/estatisticastransito/sa-frotaveiculos/d28760f78f21-429f-b039-0547c8c46ed1 Visited on 28. Jan.2018.

[18] Dubar, C. "Para uma Teoria Sociológica da Identidade". Porto: Porto Editora. 1997.

[19] Françozo, M. T..; De Mello, N. C. "Influência dos Aplicativos de Smartphones para Transporte Urbano no Transito". In: 7th Luso-Brazilian Congress for Urban, Regional, Integrated and Sustainable Planning. Maceio. 2016. 
[20] Galyani Moghaddam, G. "Information technology and gender gap: toward a global view". The Electronic Library, 2010, pp. 722-733.

[21] Gurumurthy, A. "Gender and ICTs: Overview Report", Bridge Cutting Edge Pack, Institute of Development Studies, Brighton, 2004.2 URL: http://www.bridge.ids.ac.uk/reports/cep-icts-or.pdf Visited on 13.May.2016.

[22] Hanson, S. "Gender and Mobility: New Approaches for Informing Sustainability". Gender, Place \& Culture, 2010, pp. 5-23.

[23] Ibrahim, A. M.; Adamu, M. A. "ICT Is Not Gender Blind: A Literary Analysis of ICT Gender Inequality and its Socio-Economic Impact in the Developing World." In: Overcoming Gender Inequalities through Technology Integration, IGI Global, 2016, pp. 174-193.

[24] Instituto Brasileiro de Geografia e Estatística (IBGE). "Índice de Desenvolvimento Humano". 2010a. URL: https://cidades.ibge.gov.br/brasil/to/palmas/pesquisa/37/0.

Visited on 26. Jan.2018.

[25] Instituto Brasileiro de Geografia e Estatística (IBGE). "Censo Demográfico 2010". 2010b. URL: https://www.ibge.gov.br/apps/snig/v1/?loc=0.0U\& cat =$1,1,2,-2,3,128 \&$ ind $=4710$ Visited on 09. Feb.2018.

[26] Kantor, P. "Female mobility in India: the influence of seclusion norms on economic outcomes". International Development Planning Review, 2002, pp. 145-159.

[27] Kunieda, M..; Gauthier, A. "Gender and Urban Transport: Smart and Affordable: Module 7a". Sustainable Transport Sourcebook for Policy Makers in Developing Countries. Eschborn: GTZ, 2007.

[28] Lee, A. "Gender, Everyday Mobility, and Mass Transit in Urban Asia". Mobility in History, 2017, pp. 85-94.

[29] Luciano, E. M..; Wiedenhöft, G. C.; Macadar, M. A. "The Utilização de Teorias em Pesquisas na Área de Administração da Informação no Brasil: Reflexões Iniciais". Electronic Journal of Information Systems, 2015, pp. 1.

[30] Mcgranahan, G..; Martine, G. "Urban growth in emerging economies: Lessons from the BRICS". Routledge, 2014.

[31] Metrô. "Indicadores". 2018. URL: http://www.metro.sp.gov.br/metro/index.aspx Visited on 28. Jan.2018.

[32] Miles, M. B..; Huberman, A. M.; Saldaña, J. (2014). Qualitative Data Analysis: A Sourcebook. Sage[33] Morgan, A. J. "Exploring the Influence of Human Individual Differences on Online Searching Behavior". AMCIS 2006 Proceedings, 2006, pp. 345.

[34] Nespoli, L. C. M. "Big Data para Análise de Métricas de Qualidade de Transporte: Metodologia e Aplicação". Technical Cadernos FGV, 2015.

[35] Nobre, L. "Desafios e soluções para a mobilidade urbana. Cadernos FGV Projetos - Cidades Inteligentes e Mobilidade Urbana", 2014, pp. 130-139.

[36] Primo, N. "Gender issues in the information society". Geneva: UNESCO Publications for the World Summit on the Information Society. 2003.

[37] Quaresma, M..; Gonçalves, R. C. "Análise da usabilidade de aplicativos rede social para motoristas". Arcos Design, 2013, pp. 25-52.
[38] Quesenberry, J. L.; Trauth, E. M. "The Role of Ubiquitous Computing in Maintaining Work-life Balance: Perspectives from Women in the Information Technology Workforce". In: Designing Ubiquitous Information Environments: Socio-Technical Issues and Challenges. Springer, Boston, MA, 2005. p. 43-55.

[39] Reis, M. "Mobilidade Urbana: Um Desafio Para Gestores Públicos". Cadernos FGV Projects - Intelligent Cities and Urban Mobility, 2014, pp.130-139.

[40] Richards, D..; Busch, P. "Knowing-doing Gaps in ICT: Gender and Culture". VINE, 2013, pp. 264-295.

[41] Sandelowski, M., Voils, C. I., \& Knafl, G. (2009). "On quantitizing." Journal of Mixed Methods Research, 2009, pp. 208-222.

[42] Stepulevage, L. "Gender/technology relations: Complicating the gender binary". Gender and Education, 2001, pp. 325-338.

[43] Stryker, S..; Burke, P. J. "The past, present, and future of an identity theory". Social Psychology Quarterly, 2000, pp. 284-297.

[44] Trauth, E. M. "Odd Girl Out: An Individual Differences Perspective on Women in the IT Profession. Information", Technology \& People, 2002, pp. 98-118.

[45] Trauth, E. M. "An agenda for research on gender diversity in the global information economy". Encyclopedia of gender and information technology, 2006.

[46] Trauth, E. M. "Theorizing Gender and Information Technology Research". Human Computer Interaction: Concepts, Methodologies, Tools and Applications, 2009.

[47] Trauth, E. M..; Quesenberry, J. L.; Morgan, A. J. "Understanding the under representation of women in IT: Toward a theory of individual differences". In: Proceedings of the 2004 SIGMIS conference on Computer personnel research: Careers, culture, and ethics in a networked environment. ACM, 2004, pp. 114-119.

[48] United Nations (ONU). World Urbanization Prospects. 2014.

URL:

https://esa.un.org/unpd/wup/Publications/Files/WUP2014-

Highlights.pdf Visited on: 02. Feb.2018.

[49] United Nations (ONU). Census Bureau. Worldometers, World Statistics Updated in Real Time. 2016. URL: http://www.worldometers.info/world-population/brazilpopulation/ Visited on 27.Apr.2016.

[50] Vasconcellos, E. A. "Mobilidade Cotidiana, Segregação Urbana e Exclusão". In: Balbim, R..; Krause, C..; Linke, C. C. (eds.). City and Movement: Mobility and Interactions in Urban Development. Brasília : Ipea : ITDP, 2016.

[51] Venkatesh, V..; Morris, M. G. "Why don't men ever stop to ask for directions? Gender, social influence, and their role in technology acceptance and usage behavior". MIS Quarterly, 2000, pp. 115-139.

[52] Wachs, M. "Women's Travel Issues: Creating Knowledge, Improving Policy, and Making Change." In: Transportation Research Board Conference Proceedings. 2010

[53] Wang, F. Y. "Scanning the issue and beyond: Transportation and mobility transformation for smart cities". IEEE Transactions on Intelligent Transportation Systems, 2015, pp. 525-533. 